\title{
Identification of craniofacial risk factors for obstructive sleep apnoea using three- dimensional MRI
}

\author{
L. Chi*, F-L. Comyn*, N. Mitra* , M.P. Reilly ${ }^{\mp}$ F. Wan\#, G. Maislin*, L. Chmiewski*, \\ M.D. Thorne-FitzGerald*, U.N. Victor*, A.I. Pack* and R.J. Schwab*
}

ABSTRACT: The alteration of craniofacial structures has been associated with obstructive sleep apnoea (OSA). We hypothesised that: 1) a smaller mandible is a risk factor for OSA; and 2) the previously observed inferiorly positioned hyoid bone in apnoeics is associated with enlarged tongue volume.

This is a case-control study using three-dimensional magnetic resonance imaging cephalometry. 55 apneics and 55 controls were matched for age, sex and race. The analysis was stratified by sex and controlled for age, race, height, neck visceral fat, skeletal type and tongue volume.

We found that a 1-SD increase in mandibular length and depth were associated with decreased risk of sleep apnoea (OR $0.52,95 \% \mathrm{Cl} 0.28-0.99$ and $\mathrm{OR} 0.46,95 \% \mathrm{Cl} 0.23-0.91$, respectively) in males but not in females. Greater hyoid-to-nasion (OR 2.64, 95\% $\mathrm{Cl} 1.19-5.89$ in males and OR $5.01,95 \% \mathrm{Cl} 2.00-12.52$ in females) and supramentale-to-hyoid (OR 2.39, 95\% Cl 1.12-5.14) in males and $\mathrm{OR} 3.38,95 \% \mathrm{Cl} 1.49-7.68$ in females) distances were associated with increased risk of OSA. The difference for hyoid position between apnoeics and controls was lost after controlling for tongue volume.

Enlargement of tongue is likely to be the pathogenic factor for inferior-posterior positioning of hyoid. A small and shallow mandible is an independent risk factor for OSA in males but not in females.

KEYWORDS: Cephalometrics, hyoid bone, mandible, obstructive sleep apnoea, three-dimensional magnetic resonance imaging

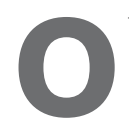
bstructive sleep apnoea (OSA) is a serious public health disorder that affects $\geqslant 4 \%$ of middle-aged males and $2 \%$ of middle-aged females in its symptomatic form (i.e. with excessive sleepiness) [1]. Accumulating evidence has suggested that OSA is an independent risk factor for hypertension, ischaemic heart disease, stroke, heart failure, atrial fibrillation and sudden death $[2,3]$, neurophysiological morbidity $[4,5]$, and insulin resistance $[6,7]$. However, we presently possess only limited knowledge of the pathogenesis and, in particular, craniofacial risk factors for this complex disorder.

OSA is mediated by several intermediate traits, such as obesity, increased soft tissue volume, altered craniofacial structure, and neuromuscular and ventilatory control [8]. A critical abnormality in patients with OSA is narrowing of the upper airway, which is detected even during wakefulness
$[9,10]$. Enlargement of the upper airway soft tissue structures, increased upper airway adipose tissue and reduction in the size of craniofacial structures have all been shown to be risk factors for OSA [10-12]. All of these factors can be examined by upper airway magnetic resonance imaging (MRI).

Cephalometry, a standardised lateral radiograph of the head and neck, has been utilised in the past to study craniofacial structures in patients with sleep apnoea. In general, these studies have shown that apnoeics have small retroposed mandibles, narrow posterior airway spaces, enlargement of the tongue and soft palate, an inferiorly positioned hyoid bone, and retroposition of the maxilla compared with nonapnoeic subjects [13-17]. These craniofacial risk factors for sleep apnoea are more commonly reported in nonobese apnoeics than in obese apnoeics [18]. Although cephalometric studies have provided insights into

\section{AFFILIATIONS}

${ }^{*}$ Center for Sleep and Respiratory Neurobiology, Division of Sleep Medicine, Dept of Medicine, ${ }^{\#}$ Center for Clinical Epidemiology and Biostatistics, Dept of

Biostatistics and Epidemiology, and "Cardiovascular Institute, University of Pennsylvania School of Medicine, Philadelphia, PA, USA.

\section{CORRESPONDENCE}

L. Chi

Center for Sleep and Respiratory

Neurobiology

University of Pennsylvania School of Medicine

3624 Market Street

Suite 205

Philadelphia

PA 19104

USA

E-mail: Luqi.Chi@uphs.upenn.edu

Received:

July 262010

Accepted after revision:

Jan 042011

First published online:

Jan 142011 
craniofacial abnormalities in patients with OSA, a meta-analysis evaluating these studies found that only one cephalometric variable, mandibular body length, demonstrated a clinically significant association with sleep apnoea [17].

There are several significant limitations to conventional cephalometrics. In addition to problems associated with standardising the radiographic equipment, technique and interpretative skills, it is difficult or impossible to perform volumetric analysis, patients are exposed to radiation, it cannot be performed in the supine position, it is a two-dimensional representation of a three-dimensional object (therefore, magnification and distortion are problems), and it only provides limited information about soft tissue lateral structures (an important disadvantage, as numerous studies show that the airway is primarily narrowed in the lateral dimension in OSA subjects) $[9,10]$.

There are significant advantages to MRI. MRI provides excellent resolution of upper airway soft tissue structures (including adipose tissue), accurately measures cross-sectional airway area and volume, allows multiplanar imaging (axial, sagittal and coronal), provides data for three-dimensional upper airway reconstructions, can be performed in the supine position during wakefulness and sleep, and does not expose patients to radiation.

We have developed MRI cephalometric techniques to study upper airway anatomical structures in two and three dimensions. These techniques allow us not only to assess standard cephalometric measurements but also provide a wealth of craniofacial information not available on standard cephalometry. We have already successfully utilised similar techniques to identify several important upper airway soft tissue structural risk factors for sleep apnoea [9, 10, 19, 20]. We demonstrated that increased volume of the tongue, lateral pharyngeal walls and total soft tissue significantly increase the risk for sleep apnoea [10]. Although we showed that the upper airway soft tissue structures are enlarged in patients with sleep apnoea, we did not previously examine craniofacial structures.

Recently, similar MRI algorithms have been used to quantify craniofacial structures and, in particular, the mandible in a study of 31 Japanese males with OSA and 20 normal controls [21]. A smaller mandibular internal length, a wider mandibular divergence and a smaller area at the mandibular base plane was found in apnoeic males compared with controls [21]. However, in that investigation, important confounders, such as age, height, body mass index (BMI) or craniofacial subtypes, were not considered.

Inferior positioning of the hyoid bone has also been documented to be associated with sleep apnoea using cephalometric techniques $[13,22-25]$. It has been proposed that the position of the hyoid bone has an impact on tongue shape and posture, thereby affecting the patency of the hypopharyngeal airway [26]. However, to our knowledge, no study has examined the actual relationship between hyoid position and tongue, as well as total upper airway soft tissue, using a threedimensional analytic approach.

In the present study, we used MRI to identify the alterations in craniofacial structures that increase the risk for OSA, using a case-control design in normal subjects and patients with sleep apnoea. Subjects with sleep apnoea and control subjects were matched for sex, ethnicity and age (within 5 yrs). We also controlled for obesity (parapharyngeal fat pad or BMI) as a covariate in our analyses. We specifically hypothesised that: 1) smaller mandibular body length, width and depth are independent risk factors for OSA; and 2) the previously observed inferior-posteriorly positioned hyoid bone in apnoeics is associated with enlarged tongue volume. Other analyses were exploratory. Some of the results of this study have been previously reported in the form of an abstract [27].

\section{METHODS \\ Subjects}

The present study used a case-control design and studied 55 cases (apnoeics) and 55 matched controls. The University of Pennsylvania (Philadelphia, PA, USA) institutional review board for human studies approved the protocol, and informed written consent was obtained from each patient. Cases were recruited primarily from the Penn Center for Sleep Disorders (Philadelphia, PA) outpatient practice and were newly diagnosed as having sleep apnoea. They had symptoms of sleep apnoea. To qualify as a case, such patients had to have an apnoea/hypopnoea index (AHI) $>15$ events $\cdot h^{-1}$. Control (normal) subjects were recruited through local advertisements in the neighbourhood (same school district) of the cases. Ethnicity was determined by self-report. Controls were of the same sex and ethnic background as the cases. To qualify as controls, individuals needed to be free of sleep apnoea. This was confirmed by a sleep study and all controls recruited had an AHI $<5$ events $\cdot h^{-1}$. Hence, we specifically examined two ends of the spectrum and excluded subjects with mild sleep apnoea. Subjects with AHI $>5$ but $\leqslant 15$ events $\cdot h^{-1}$ were considered indeterminate and were not studied further (these subjects were not included in the analysis, as they did not undergo a MRI).

\section{Polysomnography}

Standard polysomnography techniques were used (see online supplement for additional information) [28].

\section{Magnetic resonance imaging}

In the present study, upper airway imaging was performed identically in normal subjects and subjects with sleep apnoea, using a 1.5-T MRI scanner (see online supplement for additional information).

\section{Anatomical definitions and measurements}

The primary craniofacial measurements included the following. 1) Axial measurements: mandibular length and depth measured in three dimensions and mandibular width measured in two dimensions (fig. 1). 2) Midsagittal cephalometric measurements: the distance from hyoid to nasion, sella and supramentale (fig. 2a). 3) Skeletal type classifications according to relationship of maxilla and mandible (fig. 2b) [29]. Detailed explanations of three-dimensional (interslice) measurements and two-dimensional (intraslice) measurements can be found in the online supplement in figure E3. Secondary measurements included maxillary measurements, and other mandibular and cephalometric measurements (see online supplement). The three-dimensional volumetric measurements of parapharyngeal 

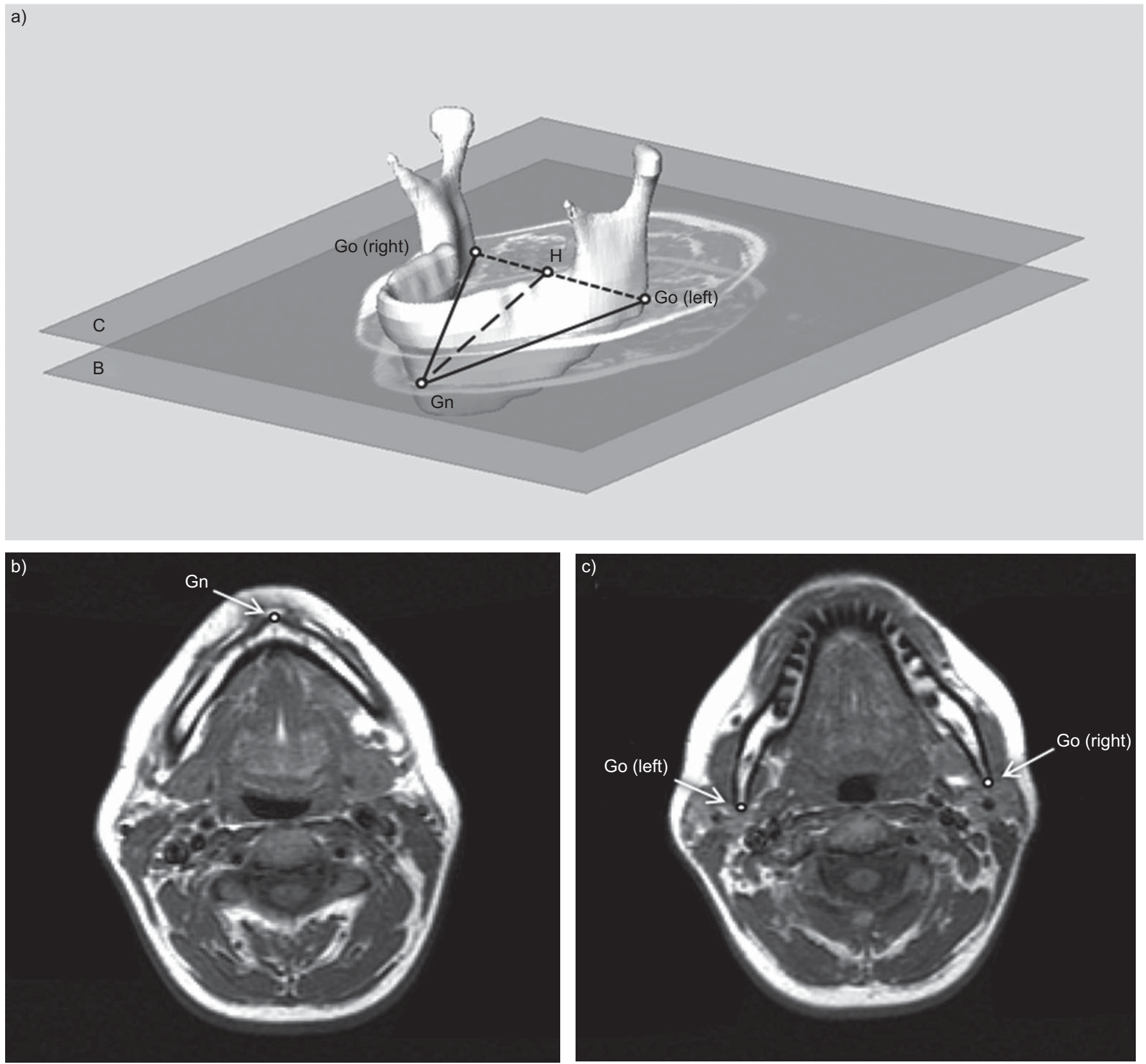

FIGURE 1. Definition of mandibular measurements and magnetic resonance imaging (MRI; T1-weighted, spin echo) correlates. a) Three-dimensional reconstruction of the mandible with craniofacial points and distance measurements. Craniofacial points are: gnathion (Gn), the most anterior-inferior point of the mandible; gonion (Go), the left and right Go are the most posterior and inferior points of the mandible. The distances measured: mandibular body length ( - ), the distance from Gn to the left or right Go; mandibular width (---), the two-dimensional measurement of the width of the lower portion of the mandible (the distance between the left and right Go); mandibular depth (-- ), the distance from Gn to $H$, where $H$ is the midpoint between the left and right Go. b) The axial MRI slice containing the Gn. c) The axial MR slice containing the left and right Go.

fat pad, tongue volume and total upper airway soft tissue volume were assessed as described in previous studies [10].

\section{Primary mandibular measurements}

Three mandibular measurements were collected to determine the dimensions of the lower portion of the mandible. The coordinates for the most anterior-inferior point of the mandible (gnathion) and the most posterior-inferior points of the mandible (left and right gonion) were identified on the corresponding MRI slices (fig. $1 \mathrm{~b}$ and c). Mandibular body length was measured as the average distance from the gnathion to the left and right gonion, and mandibular width was measured as the distance between the left and right gonion. Mandibular depth was calculated as the distance from the gnathion to the midpoint between the left and right gonion (fig. 1a). 

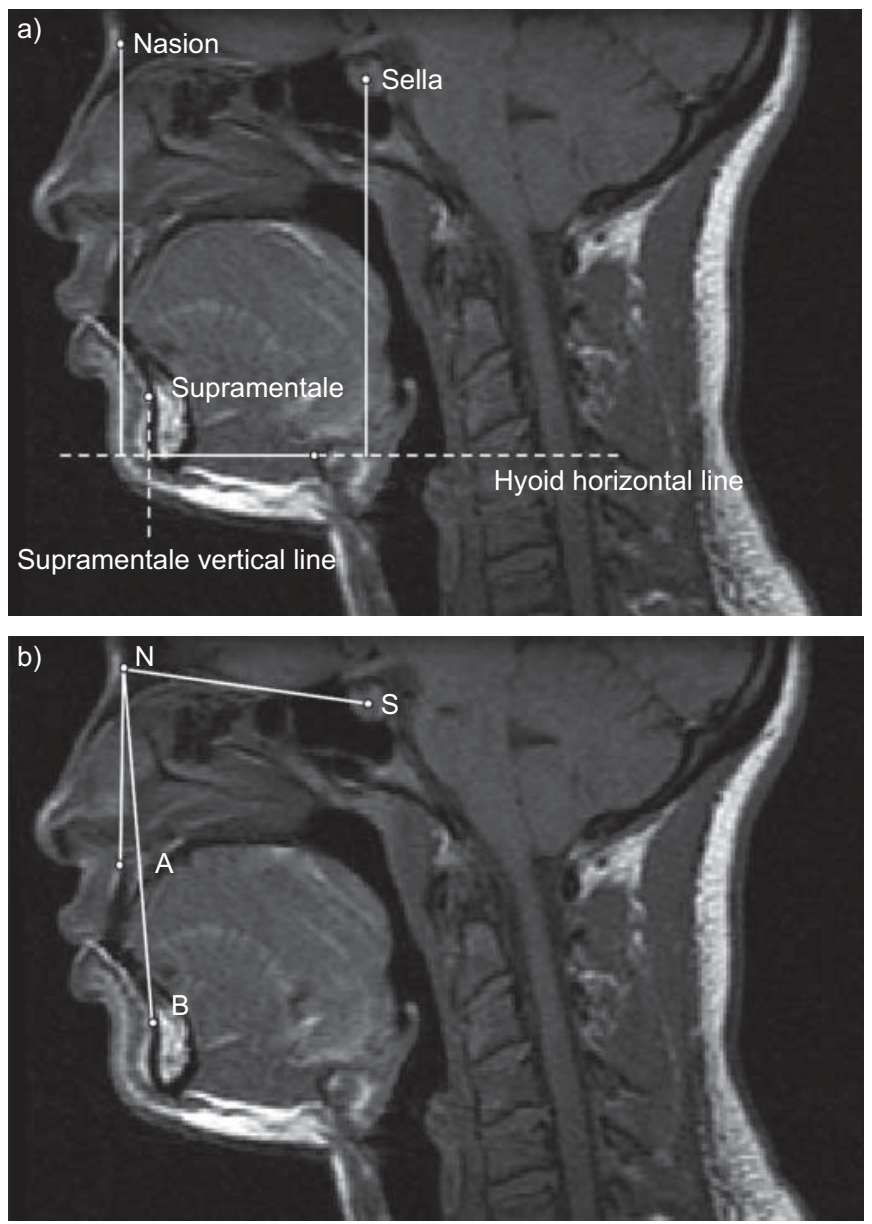

FIGURE 2. a) Midsagittal magnetic resonance imaging (MRI; T1-weighted, spin echo) slice with cephalometric hyoid measurements. Craniofacial points are: nasion, the most anterior aspect of the frontonasal suture; sella, the most anteriorinferior point of the sella turcica; supramentale, the deepest point on the curvature of the facial surface of the mandibular symphysis; hyoid bone, the most superior and anterior point on the body of the hyoid bone. The hyoid horizontal line is the horizontal line that passes through the hyoid point and extends beyond the posterior wall of the airway; the supramentale vertical line is the vertical line that passes through the supramentale and intersects with the hyoid horizontal line. The distances measured were: nasion-to-hyoid distance, the vertical line segment from the nasion to the hyoid horizontal line; sella-to-hyoid distance, the vertical line segment from the sella to the hyoid horizontal line; supramentale-to-hyoid distance, the horizontal line segment from hyoid to the supramentale vertical line. All lines and distances were measured either perpendicular or parallel to the true horizontal. b) MRI (T1-weighted, spin echo) cephalometric angular measurements. Craniofacial points are: nasion (N); sella (S); supramentale (B); and subspinale (A), the deepest point on the curvature of the facial surface of the maxilla (premaxilla). The angles measured were: the sella-nasion-subspinale (SNA) angle; the sella-nasionsupramentale (SNB) angle; and the ANB angle, the difference between the SNA and SNB angles.

\section{Midsagittal hyoid measurements}

Hyoid position is typically determined by measuring the distance between the hyoid and the mandibular plane [13]. Since the mandibular plane is not seen on the midsagittal MRI images, we did not use this measurement. Instead, we used vertical and horizontal measurements to characterise the position of the hyoid, as described previously to determine the caudal and/or inferior position of the hyoid bone [23, 24].

\section{Angular measurements and craniofacial skeletal subtype classifications}

In order to assess the position of mandible and maxilla relative to the cranial bases, the sella-nasion-subspinale (SNA), sella-nasion-supramentale (SNB) and subspinale-nasionsupramentale (ANB) angles were determined (fig. 2b) [29]. The ANB angle, the difference between the SNA and SNB angles, assessed the anterior-posterior relationship of the maxilla and the mandible in reference to the cranial base. We used the ANB angle to determine the skeletal type, as proposed by STEINER [29]. Each subject was subgrouped according to the following norms: class I, a normal anteroposterior relationship between maxilla and mandible (ANB angle $0-4^{\circ}$ for Caucasians, $4-8^{\circ}$ for African Americans and $0.5-$ $4.5^{\circ}$ for Asians); class II, a retrognathic mandible in reference to the maxilla (ANB $>4^{\circ}$ for Caucasians, $>6^{\circ}$ for African Americans and $>4.5^{\circ}$ for Asians); and class III, a prognathic mandible with a normal maxilla, or a retrognathic maxilla with a normal mandible, or a combination of a retrognathic maxilla and a prognathic mandibule (ANB $<0^{\circ}$ for Caucasians and Asians and $\mathrm{ANB}<4^{\circ}$ for African Americans) [29].

Other three- and two-dimensional mandibular, maxillary and standard MRI cephalometric measurements were examined in order to provide a more complete assessment of craniofacial risk factors for OSA. However, these a priori exploratory analyses lacked the power to detect small effects, especially given multiple testing and subgroup analysis. The results of these exploratory analyses are provided in the online supplement.

\section{Measurement reliability study}

In order to demonstrate reliability, the six primary variables (mandibular length, width, depth, and three hyoid bone position variables) in the present study were analysed in 10 randomly selected subjects by two readers. Each variable was measured three times over three separate days to reduce recall bias by the two different readers. The order of the images analysed on a given day was randomised. Intra- and interreader reliability were then analysed.

\section{Statistical analysis}

Baseline characteristics of case and control subjects were compared using Chi-squared tests for categorical variables and unpaired t-tests for continuous variables (or rank-based procedures for nonparametric data, if specified). Mandibular length, width and depth, and three hyoid bone position variables were the primary measurements in the analysis. Secondary analysis focused on maxillary and other madibular and hyoid variables.

We matched cases and controls for age (within $5 \mathrm{yrs}$ ). We controlled for age, height, parapharyngeal fat pad volume or $\mathrm{BMI}$, and tongue volume or total soft tissue volume [10] in each sex stratum, using linear regression models to determine the association of those craniofacial risk factors for OSA. We controlled for fat pad volume, a measure of the relevant visceral adiposity in the neck, as BMI may be influenced by nonfat mass as well as adipose deposits in other subcutaneous and central locations [10]. Nonetheless, we performed the 
analysis controlling for each of these variables. Mandibular body length, width and depth may be correlated with each other; therefore, a multivariable logistic regression analysis was performed, which encompassed all the a priori factors (mandibular length, width and depth, or hyoid bone measurements) as well as confounding factors. This model took into account any correlation between the measurements and independently examined the increase in risk of sleep apnoea for each of these factors. Within each sex stratum, multivariable logistic regression models were used to obtain adjusted odds ratios and $95 \%$ confidence intervals for the effects of a 1-SD change in the size of the craniofacial measurements. Since multiple regression models were fit to the data, the conservative Bonferroni multiple testing correction was applied to all primary hypotheses tests.

Intrareader reliability for MRI measurements was analysed by the intraclass correlation coefficient (ICC). To compute the ICC, we used mixed-effect models for each variable, using a compound symmetric correlation structure. Inter-reader reliability was analysed by two-way ANOVA with main random effects for variable and reader. All analyses were conducted using SAS version 9.1 (SAS Institute Inc., Cary, NC, USA).

We based power calculations on the smallest sex stratum available to provide the lower bound on power. The only available volumetric MRI study [21] demonstrated a 3.5-mm mandibular body length difference between male cases and controls with an SD of $4.2 \mathrm{~mm}$. Hence, we based our calculations on this effect size. Using a two-sided t-test with significance level of $0.05,27$ male apnoeics, and 27 male nonapnoeics, with SD $4.2 \mathrm{~mm}$, our study had $85 \%$ power to detect this demonstrated effect size. The Power and Sample Size Calculation program, version 2.1.31 (Vanderbilt University, Nashville, TN, USA) was used for power calculations.

\section{RESULTS}

\section{Demographics of case and control subjects}

Pertinent characteristics of the study sample are summarised in tables 1 and 2. There were no significant differences between the height of apnoeics and controls. Cases tended to be older than the controls, but this difference was not statistically significant. The BMI of cases was significantly greater than that of controls, but many controls were overweight. As expected by design, patients with sleep apnoea had significantly greater mean AHI than nonapnoeic controls (table 1). There were no differences in skeletal types between apnoeics and controls in the full sample or within sex strata (table 2). There were no differences in marital status and education between controls and apnoeics (see table E1 in online supplement). More of the female cases and controls were African American compared with male cases and controls.

\section{Polysomnography}

As shown in table E2 (see online supplement), sleep efficiency was not different between cases and controls $(p=0.91)$, and there were no significant differences between the mean time spent in stage $1(p=0.21)$ and stage 2 sleep $(p=0.61)$. Cases had significantly less rapid eye movement sleep than did controls $(p=0.01)$ and tended to have less delta sleep $(p=0.06)$. There were significantly more nocturnal arousals among cases than controls $(\mathrm{p}<0.0001)$.

\section{Measurement reliability analysis}

In our intrareader reliability study, the interclass correlation efficient was $>0.98$ for the MRI craniofacial measurements (see online supplement table E3a). In our inter-reader reliability study, the percentage of total variance attributable to between reader variations was $<1 \%$ (see online supplement table E3b). Therefore, our MRI measurements are highly reproducible based on our excellent agreement between and within the two readers.

\section{MRI mandibular measurements}

Unadjusted mean mandibular comparisons between apnoeics and controls are shown in table 3. Before the stratification for sex, the mandibular length and depth were smaller, and the mandibular width was larger in cases than in controls, but these differences did not reach a significant level $(p=0.24$, $p=0.26$ and $p=0.12$, respectively). After stratification for sex (table 3), the unadjusted means of mandibular length and depth were significantly smaller in cases than in controls in males $(p=0.04$ and $p=0.02$, respectively), but not in females.

Table 4 shows differences in means of mandibular measurements between cases and controls, adjusting for important confounding risk factors. After adjusting for ethnicity, age, height, skeletal type (ANB angle) and parapharyngeal fat pad volume, mandibular length and depth were significantly

TABLE 1 Demographics of apnoeic and normal subjects

\begin{tabular}{|c|c|c|c|}
\hline & Cases & Controls & $p$-value \\
\hline Subjects n & 55 & 55 & \\
\hline \multirow[t]{2}{*}{ Age yrs } & $44.5 \pm 9.7$ & $41.0 \pm 10.2$ & $0.07^{\circ}$ \\
\hline & $47.0(27.0-63.0)$ & $42.0(24.0-66.0)$ & \\
\hline \multirow[t]{2}{*}{ Height $\mathbf{c m}$} & $171.0 \pm 10.6$ & $171.7 \pm 9.2$ & $0.72^{\circ}$ \\
\hline & $170.2(149.9-193.0)$ & $170.2(152.4-190.5)$ & \\
\hline \multirow[t]{2}{*}{ Weight kg } & $101.6 \pm 19.4$ & $80.4 \pm 16.1$ & $<0.0001^{\circ}$ \\
\hline & $104.8(56.2-138.6)$ & $72.6(48.1-127.9)$ & \\
\hline \multirow[t]{2}{*}{ BMI $\mathbf{k g} \cdot \mathbf{m}^{-2}$} & $35.5 \pm 8.5$ & $25.9 \pm 4.5$ & $<0.0001^{\circ}$ \\
\hline & $32.9(20.6-52.9)$ & $24.8(19.4-42.8)$ & \\
\hline \multirow[t]{2}{*}{ AHI events $\cdot h^{-1}$} & $46.8 \pm 33.5$ & $2.2 \pm 1.7$ & $<0.0001^{+}$ \\
\hline & $33.5(15.1-142.0)$ & $1.8\left(0.0-6.3^{\#}\right)$ & \\
\hline Males & $27.0(49.0)$ & $27.0(49.0)$ & 1.0000 \\
\hline \multicolumn{4}{|l|}{ Race } \\
\hline White & $25(45.5)$ & $25(45.5)$ & \\
\hline African American & $27(49.1)$ & $27(49.1)$ & \\
\hline Asian & $2(3.6)$ & $2(3.6)$ & \\
\hline Hispanic & $1(1.8)$ & $1(1.8)$ & \\
\hline
\end{tabular}

Data are presented as mean $\pm \mathrm{SD}$, median (range) or $n(\%)$, unless otherwise stated. Significant difference $(\mathrm{p}<0.05)$ are presented in bold. BMI: body mass index; $\mathrm{AHI}$ : apnoea/hypopnoea index. \#: four control subjects had an $\mathrm{AHI}$ between 5 and 6 events $\cdot h^{-1}\left(5.3,5.4,5.7\right.$ and 6.3 events $\left.\cdot h^{-1}\right)$; although they did not quite meet the protocol guidelines for a control subject ( $\mathrm{AHI} \leqslant 5$ events $\cdot \mathrm{h}^{-1}$ ), they met all other criteria, so we did not exclude them due to this slight elevation (results shown here remained the same when these subjects were excluded from the analysis; data not shown). ${ }^{\bullet}$ : t-test. ${ }^{+}$: Wilcoxon rank test. 
TABLE 2 Populations of apnoeic and normal subjects according to craniofacial skeletal type and sex

\begin{tabular}{|c|c|c|c|c|c|c|c|c|c|c|}
\hline & \multirow[t]{2}{*}{ Total } & \multicolumn{2}{|c|}{ All subjects } & \multirow[t]{2}{*}{ p-value } & \multicolumn{2}{|c|}{ Males } & \multirow[t]{2}{*}{ p-value } & \multicolumn{2}{|c|}{ Females } & \multirow[t]{2}{*}{ p-value } \\
\hline & & Apnoeic & Normal & & Apnoeic & Normal & & Apnoeic & Normal & \\
\hline $\begin{array}{l}\text { Subjects } \mathrm{n} \\
\text { Skeletal type }\end{array}$ & $107^{\#}$ & $52^{\#}$ & 55 & & 24 & 27 & & 28 & 28 & \\
\hline Class I & $60(56)$ & 31 (59) & 29 (53) & 0.67 & 14 (58) & $13(48)$ & 0.55 & 17 (61) & $16(57)$ & 0.96 \\
\hline
\end{tabular}

Data are presented as $\mathrm{n}(\%)$, unless otherwise stated. ${ }^{*}$ : sella-nasion-subspinale, sella-nasion-supramentale and subspinale-nasion-supramentale angles were not obtained in three subjects due to artefacts on midsagittal magnetic resonance imaging; ${ }^{\bullet}$ : Chi-squared test.

smaller in cases than in controls in males $(\mathrm{p}=0.01$ and $\mathrm{p}<0.01$, respectively). The smaller mandibular length and depth remained significant even after using stringent Bonferroni corrections for multiple testing. However, the differences in mandibular length, width and depth between apnoeic and normal females were not statistically significant in any of the models.

These findings remained significant after further controlling for tongue volume (table 4). The analysis was also performed, including total upper airway soft tissue volume in place of tongue volume (see online supplement table E4a), which showed similar results. We adjusted for neck fat rather than

\begin{tabular}{l} 
TABLE $3 \begin{array}{c}\text { Mean comparison of mandibular measurements } \\
\text { between apnoeic and normal subjects }\end{array}$ \\
\multicolumn{5}{c}{ Apnoeic } & Normal & Difference \% & p-value ${ }^{\#}$ \\
\hline
\end{tabular}

Data are presented as mean $\pm S D$, unless otherwise stated. Significant differences $(p<0.05)$ are presented in bold. Body length: average left and right mandibular body length. Difference: apnoeic - normal. ${ }^{*}$ : t-test. " : mandibular measurements were not obtained in one subject due to magnetic resonance imaging artefacts

BMI, as fat surrounding the upper airway may be much more important in mediating the pathogenesis of sleep apnoea than BMI, which is a global measure of fat. However, we repeated the analyses using BMI in place of fat pad volume as a covariate and the results were similar (see online supplement table E4b).

In males, the unadjusted odds ratios for a 1-SD increase in mandibular body length and mandibular depth were significantly smaller than one, indicating increased risk of sleep apnoea among subjects with a shorter mandibular body length, and a shallower mandibular depth (table 5). Results were similar after adjusting for race, age, height, skeletal type (ANB angle) and parapharyngeal fat pad volume. Further controlling for tongue volume did not alter the magnitude of odds ratios. Replacing the volume of the parapharyngeal fat pad and tongue volume with total soft tissue volume showed the same results (see online supplement table E5a) or including BMI in

\section{TABLE 4 Comparison of adjusted mean differences in mandibular measurements between apnoeic and normal subjects, stratified by sex}

\begin{tabular}{|c|c|c|c|c|}
\hline \multirow{2}{*}{$\begin{array}{l}\text { Mandibular } \\
\text { measurements } \mathrm{mm}\end{array}$} & \multicolumn{2}{|c|}{ Model $1^{\#}$} & \multicolumn{2}{|c|}{ Model $2^{\circ}$} \\
\hline & Difference & $\mathrm{p}$-value & Difference & $p$-value \\
\hline \multicolumn{5}{|l|}{ Males } \\
\hline Body length & $-3.36 \pm 1.26$ & $<0.01^{+}$ & $-3.54 \pm 1.38$ & 0.01 \\
\hline Width & $2.12 \pm 1.71$ & 0.22 & $1.43 \pm 1.87$ & 0.45 \\
\hline Depth & $-3.74 \pm 1.42$ & $<0.01^{+}$ & $-3.78 \pm 1.30$ & $<0.01^{+}$ \\
\hline \multicolumn{5}{|l|}{ Females } \\
\hline Body length & $1.01 \pm 1.39$ & 0.47 & $0.74 \pm 1.83$ & 0.69 \\
\hline Width & $2.11 \pm 1.42$ & 0.15 & $-0.22 \pm 1.80$ & 0.90 \\
\hline Depth & $1.55 \pm 1.61$ & 0.34 & $1.52 \pm 2.12$ & 0.48 \\
\hline
\end{tabular}

Data are presented as mean $\pm \mathrm{SE}$, unless otherwise stated. Significan differences $(p<0.05)$ are presented in bold. Difference: apnoeic - normal \#: adjusted for race, age, height, fat pad volume and subspinale-nasionsupramentale (ANB) angle; '? adjusted for race, age, height, fat pad volume, ANB angle and tongue volume; ${ }^{+}$: significant after Bonferroni correction for multiple testing for all hypothesis tests. 
TABLE 5 Comparison of odds ratios in mandibular measurements between apnoeic and normal subjects, stratified by sex

\begin{tabular}{|c|c|c|c|c|}
\hline Mandibular measurements $\mathrm{mm}$ & SD & Unadjusted & Model $1^{\#}$ & Model 2 \\
\hline \multicolumn{5}{|l|}{ Males } \\
\hline Width & 5.82 & $1.54(0.84-2.84)$ & $1.65(0.78-3.42)$ & $1.34(0.61-2.95)$ \\
\hline Depth & 5.40 & $0.46(0.23-0.91)$ & $0.19(0.06-0.64)$ & $0.20(0.05-0.76)$ \\
\hline \multicolumn{5}{|l|}{ Females } \\
\hline Depth & 6.54 & $1.10(0.65-1.88)$ & $1.55(0.69-3.50)$ & $1.07(0.31-3.74)$ \\
\hline
\end{tabular}

Data are presented as OR (95\% Cl), unless otherwise stated. ORs shown are for a 1-SD increase. Significant differences $(95 \%$ Cls not including 1.0$)$ are presented in bold.

\#: adjusted for race, age, height, fat pad volume and subspinale-nasion-supramentale (ANB) angle; ": adjusted for race, age, height, fat pad volume, ANB angle and tongue volume.

place of fat pad as a confounder did not alter the results (see online supplement table E5a and b). In females, however, mandibular length and depth were not associated with increased risk for OSA before and after these adjustments. Mandibular width was not associated with increased risk for

\section{TABLE 6 Mean comparison of hyoid measurements between apnoeic and normal subjects before and after stratification for sex}

\begin{tabular}{|c|c|c|c|c|}
\hline & Apnoeic & Normal & Difference \% & p-value ${ }^{\#}$ \\
\hline \multicolumn{5}{|l|}{ All subjects } \\
\hline Subjects $n$ & $51^{\circ}$ & 55 & & \\
\hline $\begin{array}{l}\text { Hyoid-to-sella } \\
\text { distance mm }\end{array}$ & $110.4 \pm 9.7$ & $105.1 \pm 10.1$ & 4.7 & $<0.01$ \\
\hline $\begin{array}{l}\text { Hyoid-to-nasion } \\
\text { distance mm }\end{array}$ & $131.7 \pm 9.7$ & $123.5 \pm 9.5$ & 6.2 & $<0.0001$ \\
\hline $\begin{array}{l}\text { Hyoid-to-supramentale } \\
\text { mm }\end{array}$ & $58.8 \pm 7.4$ & $52.7 \pm 7.1$ & 10.4 & $<0.0001$ \\
\hline \multicolumn{5}{|l|}{ Males } \\
\hline Subjects $n$ & $23^{\bullet}$ & 27 & & \\
\hline $\begin{array}{l}\text { Hyoid-to-sella } \\
\text { distance mm }\end{array}$ & $117.1 \pm 8.2$ & $112.9 \pm 6.4$ & 3.6 & 0.047 \\
\hline $\begin{array}{l}\text { Hyoid-to-nasion } \\
\text { distance mm }\end{array}$ & $136.7 \pm 9.6$ & $129.2 \pm 8.0$ & 5.4 & $<0.01$ \\
\hline $\begin{array}{l}\text { Hyoid-to-supramentale } \\
\text { mm }\end{array}$ & $60.0 \pm 6.2$ & $54.6 \pm 7.1$ & 9.0 & $<0.01$ \\
\hline \multicolumn{5}{|l|}{ Females } \\
\hline Subjects n & 28 & 28 & & \\
\hline $\begin{array}{l}\text { Hyoid-to-sella } \\
\text { distance mm }\end{array}$ & $102.1 \pm 7.1$ & $97.7 \pm 6.9$ & 4.3 & $<0.001$ \\
\hline $\begin{array}{l}\text { Hyoid-to-nasion } \\
\text { distance mm }\end{array}$ & $127.5 \pm 7.8$ & $118.1 \pm 7.5$ & 7.4 & $<0.0001$ \\
\hline $\begin{array}{l}\text { Hyoid-to-supramentale } \\
\text { mm }\end{array}$ & $57.9 \pm 8.2$ & $50.9 \pm 6.7$ & 12.0 & 0.001 \\
\hline
\end{tabular}

Data are presented as mean $\pm S D$, unless otherwise stated. Significant differences $(p<0.05)$ are presented in bold. Difference: apnoeic - normal. \#: t-test. ": hyoid measurements were not obtained in four subjects due to magnetic resonance imaging artefacts. sleep apnoea in either males or females. There was a trend that increased mandibular width was predictive of OSA in females (OR 1.09-1.9); however, these findings were not statistically significant, as indicated by all 95\% CIs including 1.0 (table 6).

\section{Hyoid measurements using MRI}

Figure 3 demonstrates the enlarged tongue volume and inferior-posterior positioning of the hyoid in a case compared with a control. Unadjusted analyses revealed a significant inferior-posterior displacement of the hyoid bone in cases with sleep apnoea compared with controls in the full sample and after stratifying by sex ( $\mathrm{p}$-value ranging from $<0.0001$ to 0.047 ) (table 6).

The differences in mean hyoid measurements between apnoeics and normal subjects after adjusting for confounders are shown in table 7 . The vertical distance between sella or nasion

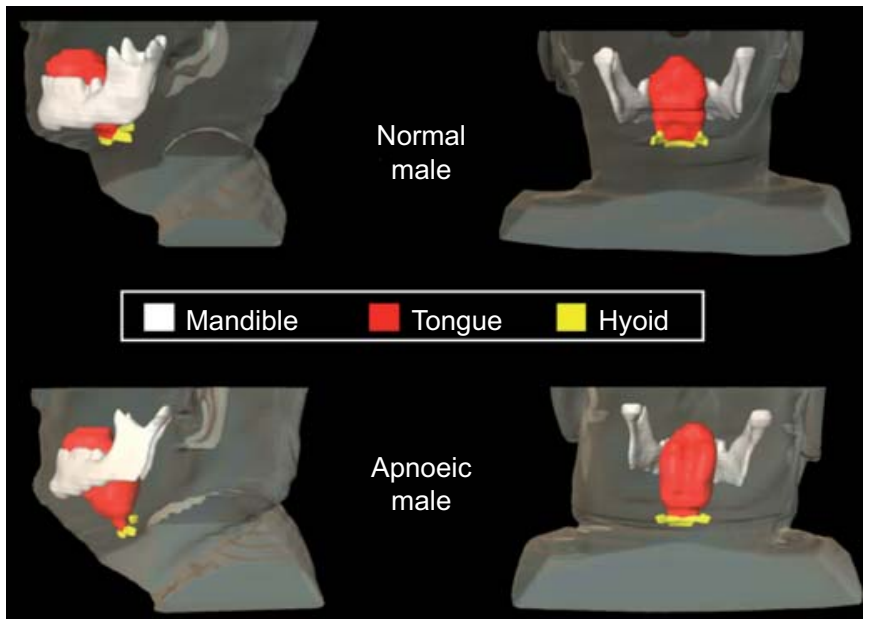

FIGURE 3. Illustration of inferior-posterior positioning of hyoid and enlarged tongue volume. Three-dimensional reconstruction of hyoid, tongue and mandible in a patient with sleep apnoea (bottom; apnoea/hypopnoea index (AHI) 86 events $\cdot \mathrm{h}^{-1}$; body mass index (BMl) $31 \mathrm{~kg} \cdot \mathrm{m}^{-2} ; 49 \mathrm{yrs}$ of age; male) and a normal subject (top; AHI 5 events $\cdot \mathrm{h}^{-1}$; BMI $25 \mathrm{~kg} \cdot \mathrm{m}^{-2} ; 44 \mathrm{yrs}$ of age; male). Note that the hyoid is more inferior-posteriorly positioned in the apnoeic subject than in the normal subject; tongue volume is greater in the apnoeic subject $\left(115.7 \mathrm{~cm}^{3}\right)$ than in the normal subject $\left(100.0 \mathrm{~cm}^{3}\right)$. 


\begin{tabular}{|c|c|c|c|c|c|}
\hline TABL & \multicolumn{5}{|c|}{$\begin{array}{l}\text { Comparison of adjusted mean differences in } \\
\text { hyoid measurements between apnoeic and } \\
\text { normal subjects, stratified by sex }\end{array}$} \\
\hline \multirow{2}{*}{\multicolumn{2}{|c|}{ Hyoid measurements $\mathrm{mm}$}} & \multicolumn{2}{|c|}{ Model $1^{\#}$} & \multicolumn{2}{|c|}{ Model $2^{\bullet}$} \\
\hline & & Difference & p-value & Difference & $p$-value \\
\hline \multicolumn{6}{|l|}{ Males } \\
\hline \multicolumn{2}{|c|}{$\begin{array}{l}\text { Hyoid-to-sella } \\
\text { distance mm }\end{array}$} & $4.10 \pm 2.22$ & 0.07 & $2.96 \pm 2.42$ & 0.23 \\
\hline \multicolumn{2}{|c|}{$\begin{array}{l}\text { Hyoid-to-nasion } \\
\text { distance } \mathrm{mm}\end{array}$} & $7.37 \pm 2.72$ & $<0.01^{+}$ & $5.47 \pm 2.88$ & 0.06 \\
\hline \multicolumn{2}{|c|}{$\begin{array}{l}\text { Hyoid-to-supramentale } \\
\text { distance mm }\end{array}$} & $4.72 \pm 2.0$ & 0.02 & $3.37 \pm 2.11$ & 0.12 \\
\hline \multicolumn{6}{|l|}{ Females } \\
\hline \multicolumn{2}{|c|}{$\begin{array}{l}\text { Hyoid-to-sella } \\
\text { distance mm }\end{array}$} & $7.70 \pm 2.0$ & $<0.001^{+}$ & $4.42 \pm 2.57$ & 0.09 \\
\hline \multicolumn{2}{|c|}{$\begin{array}{l}\text { Hyoid-to-nasion } \\
\text { distance } \mathrm{mm}\end{array}$} & $9.55 \pm 2.23$ & $<0.0001^{+}$ & $3.44 \pm 2.62$ & 0.20 \\
\hline \multicolumn{2}{|c|}{$\begin{array}{l}\text { Hyoid-to-supramentale } \\
\text { distance } \mathrm{mm}\end{array}$} & $6.86 \pm 2.31$ & $<0.01^{+}$ & $3.15 \pm 2.92$ & 0.29 \\
\hline
\end{tabular}

Data are presented as mean $\pm \mathrm{SE}$, unless otherwise stated. Significant differences $(p<0.05)$ are presented in bold. Difference: apnoeic - normal. \#: adjusted for race, age, height, fat pad volume and subspinale-nasionsupramentale (ANB) angle; ": adjusted for race, age, height, fat pad volume, ANB angle and tongue volume; ${ }^{+}$: significant after Bonferroni correction for multiple testing for all hypothesis tests.

and a horizontal line passing through the hyoid is greater in apnoeics, both males and females, than in controls. The increase in this distance indicates the inferior positioning of the hyoid. Increase of the horizontal distance between the hyoid and a vertical line passing through the supramentale indicates posterior positioning of the hyoid. After adjusting for ethnicity, age, height, skeletal type (ANB angle) and parapharyngeal fat pad volume, inferior-posterior positioning of the hyoid remained significantly associated with risk of OSA in males $(p<0.01$ for hyoid-to-nasion and $p=0.03$ for hyoidto-supramentale) and female $(\mathrm{p}<0.001$ for hyoid-to-sella, $\mathrm{p}<0.0001$ for hyoid-to-nasion and $\mathrm{p}=0.001$ for hyoid-tosupramentale). However, after controlling for total tongue volume in addition to the previous adjustments, the differences between apnoeics and normal subjects became insignificant overall, and in males and female separately.

Adjusting for upper airway total soft tissue volume in place of total tongue volume (see online supplementary table E6a) or including BMI in place of fat pad as a confounder led to identical conclusions (see online supplement table E6b).

The unadjusted odds ratios for the majority of hyoid measurements were significantly greater than one (table 8), indicating that an inferior-posterior positioning of the hyoid bone was associated with an increased risk of sleep apnoea. After adjusting for race, age, height and parapharyngeal fat pad volume: 1) vertical hyoid-to-sella distance was not associated with increased risk of sleep apnoea in males, but it was associated with increased risk in females; 2) vertical hyoidto-nasion distance was associated with increased risk in both males and females; and 3) horizontal supramentale-to-hyoid distance was also associated with increased risk in both males and females. The associations of all measures (except hyoid-tonasion in males, and this odds ratio was reduced in magnitude) of hyoid position were no longer significant after additional adjustment for tongue volume.

Adjusting for upper airway total soft tissue volume in place of total tongue volume (see online supplement table E7a) or including BMI in place of fat pad as a confounder in the models adjusting for tongue volume (see online supplement table E7b) showed similar results.

Moreover, a correlation analysis was performed in order to identify the relationship between hyoid position and tongue volume or AHI. The data showed that tongue volume was closely related to AHI and hyoid displacement. Hyoid displacement (which was secondary to increased tongue volume) was also correlated with AHI (table 9).

In exploratory analyses, we did not identify additional mandibular or maxillary measurements that were risk factors for sleep apnoea in either males or females after adjusting for confounders and controlling for multiple testing using Bonferroni corrections. These are included in the online supplement in tables E8-E19.

TABLE 8 Comparison of odds ratios in hyoid measurements between apnoeic and normal subjects, stratified by sex

\begin{tabular}{|c|c|c|c|c|}
\hline Hyoid measurements $\mathrm{mm}$ & SD & Unadjusted & Model $1^{\#}$ & Model $2^{\circ}$ \\
\hline \multicolumn{5}{|l|}{ Males } \\
\hline Hyoid-to-sella & 7.54 & $1.88(0.98-3.60)$ & $1.94(0.92-4.10)$ & $1.72(0.77-3.87)$ \\
\hline Hyoid-to-nasion & 9.44 & $2.68(1.25-5.75)$ & $2.91(1.21-7.00)$ & $2.57(1.02-6.51)$ \\
\hline Hyoid-to-supramentale & 7.16 & $2.42(1.22-4.80)$ & $2.63(1.15-6.00)$ & $2.27(0.93-5.56)$ \\
\hline \multicolumn{5}{|l|}{ Females } \\
\hline Hyoid-to-supramentale & 8.21 & $3.10(1.45-6.64)$ & $3.08(1.30-7.34)$ & $2.68(0.58-12.33)$ \\
\hline
\end{tabular}

Data are presented as OR (95\% Cl), unless otherwise stated. ORs shown are for a 1-SD increase. Significant differences (95\% Cls not including 1.0) are presented in bold.

\# : adjusted for race, age, height, fat pad volume and subspinale-nasion-supramentale (ANB) angle; ${ }^{\bullet}$ : adjusted for race, age, height, fat pad volume, ANB angle and tongue volume. 


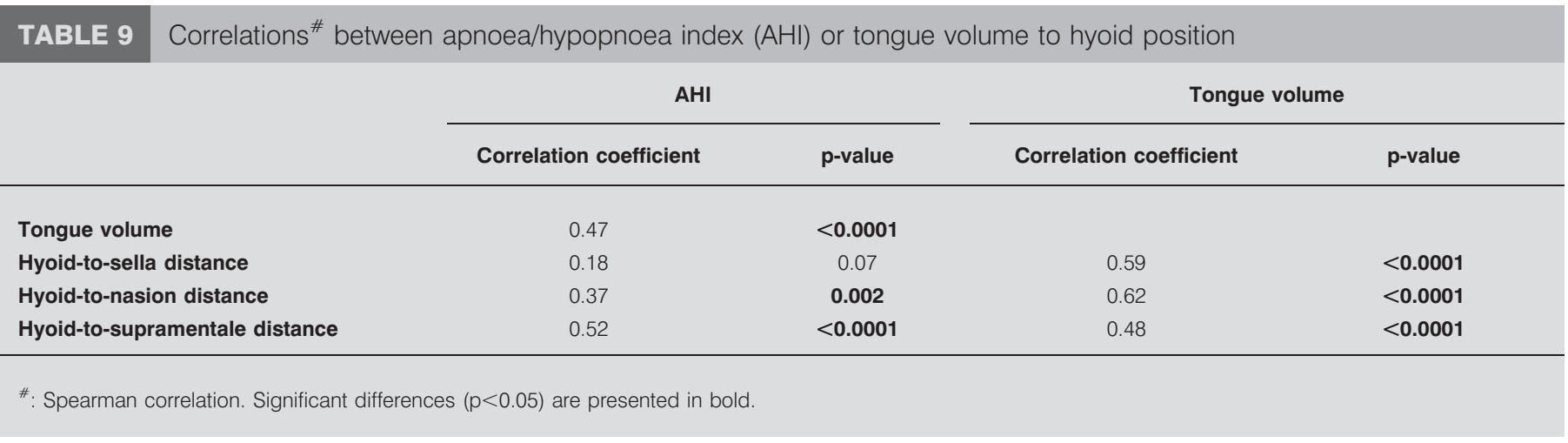

\section{DISCUSSION}

This is the first study that has used two- and three-dimensional MRI in a large population to examine the differences of the entire craniofacial structure between nonapnoeic and apnoeic subjects. After controlling for important confounders, we found the following. 1) A smaller and shallower mandible was an independent risk factor for OSA in males, but not females. 2) We confirmed the inferior displacement of the hyoid in apnoeics compared with controls; the enlargement of the tongue appears to be the pathogenic factor for inferiorposterior hyoid bone position in apnoeics, as when controlling for tongue volume, there were no differences between controls and apnoeics in the position of the hyoid. 3) The size of the mandible (length and depth) was a much more important risk factor for OSA than maxillary measures or angular measurements (SNA and SNB, etc.) in our cohort.

\section{Potential bias and limitations of this study}

There are several potential limitations of the present study that need to be discussed. We had more Caucasian male apnoeics than African American male apnoeics, and fewer Caucasian female apnoeics than African American female apnoeics (see online supplement table E1). However, in our study, cases and controls were exactly matched on sex and race separately (table 1), and the joint distribution of sex and race was also exactly balanced between apnoeics and nonapnoeics. Hence, overall differences between cases and controls are unbiased with respect to race and sex. However, our female sample was largely African American (74\%), while our male sample was largely Caucasian (66\%). Ideally, the analysis should be conducted to investigate race-specific differences within each sex. However, our sample size in race-sex subgroups did not provide the required power to make these within-stratum comparisons. We have, as a first step in this investigation, included subjects from different ethnic backgrounds and controlled for race as a covariate. This is a fairly standard initial approach. Future studies will need to address these questions in different relatively homogenous ethnic groups to evaluate ethnic-specific effects.

Measurement error could also have been a problem in this study. However, we followed identical protocols and used the same MRI machine to obtain measurements for both cases and controls. We also assessed the reliability of our measurements of mandible length, etc. We did so by performing repeated measurements on 10 subjects and found that the intraclass correlation was very high, indicating that measurement error is low. We found that our reliability coefficients for the variables we assessed were extremely high.

Another concern was related to the precision of our MRI measurements, with the differences in mandibular length between groups being, on average, $4 \mathrm{~mm}$. 5-mm slices were used to reconstruct the complete mandible and other upper airway structures. The reconstructions interpolate between adjacent slices and hence, the structures are reconstructed in a continuous fashion. Hence, the measurements are continuous rather than in 5-mm intervals. We also found that our reliability coefficients for mandibular length were extremely high. Given the high reliability, the differences in mandibular length between cases and controls, which were $4 \mathrm{~mm}$ on average, can be determined. Indeed, the mean difference was $3.5-3.8 \mathrm{~mm}$ and the standard error was $1.3-1.4 \mathrm{~mm}$; the observed effect size was 2.5 for mandibular length after adjusting for important confounders, indicating a statistical difference from zero and, therefore, the measurement error should not be an issue. Moreover, we examined the standard error of our measurements. If the standard error is low, then the issue of 5-mm MRI slices versus 4-mm measurement differences is not a concern. Our data show that the standard errors of the differences were quite small $(<1.3 \mathrm{~mm})$, demonstrating that our results (plus or minus the standard error) were within the 5-mm range.

We performed the craniofacial MRI analysis in the same patients that we had used in our previous study of soft tissue structures [10]. However, the measurements that we obtained and the hypotheses that we tested in the current study are different from those previously reported [10]. Hence, we only corrected for multiple testing within the context of the current study. We did, however, use a stringent and conservative multiple testing correction (Bonferroni correction) in this study to account for the multiple variables we tested.

We did not exclude four control subjects who met all other criteria but had a slightly elevated AHI between 5.3 and 6.3 events $\cdot h^{-1}\left(5.3,5.4,5.7\right.$ and 6.3 events $\left.\cdot h^{-1}\right)$. Our results remain the same when these four subjects were excluded from the analysis (data not shown), although they did not quite meet the protocol guidelines for a control subject (AHI $<5$ events $\cdot h^{-1}$ ).

MRI cephalometry is a powerful imaging modality to study the craniofacial structure in two and three dimensions. However, conventional cephalometric radiographs have been the primary imaging modality to examine the craniofacial structure in 
apnoeics. Unfortunately there are several significant limitations to conventional cephalometric radiographs (see Introduction). We have compared MRI to conventional cephalometric radiographs in 10 subjects to confirm the validity of our technique. These data showed there were no significant differences between several standard cephalometric measurements made using conventional cephalometric radiographs and those same measurements made using MRI. The ICCs were very high (0.77-0.99) (see online supplement table E3a-c). Therefore, these data indicate that MRI is a valid and robust technique to detect standard cephalometric landmarks.

\section{Craniofacial risk factors for OSA}

Alterations in craniofacial structure are known to be an important risk factor for sleep apnoea [13-18, 21-26], as reduction in size of the craniofacial skeleton can lead to reductions in airway calibre. Several cephalometric studies have demonstrated craniofacial abnormalities in patients with OSA compared with age- and sex-matched controls [17, 26]. A study by OKUBO et al. [21] examined mandibular dimensions in nonapnoeic and apneic subjects using MRI. They noted a significantly smaller mandibular internal length, mandibular divergence (the angle between the spina mentalis and the left internal gonion line, and the spina mentalis and the right internal gonion line) and mandibular enclosed area measured at mandibular plane in subjects with sleep apnoea than in control subjects. Those results may imply a smaller mandibular depth in patients with OSA compared with controls. The present data support the findings from that study by showing the size of the mandible, rather than the maxilla or angular measurements, may be a more important risk factor for OSA. But in addition, we also showed a sex effect in these craniofacial risk factors for OSA. We demonstrated that smaller mandibular body length and mandibular depth are independent risk factors for OSA in males but not females. However, most of the females were African American, hence, these differences could also be related to ethnicity.

\section{Aetiology of hyoid displacement}

An important finding of our study is that the hyoid bone is displaced to a more posterior and caudal position in apnoeics as compared with controls, as has been shown in previous studies [30-32]. Our results confirm this observation and provide new information as to the aetiology of the hyoid displacement. It has been speculated that the position of hyoid bone is crucial to pharyngeal patency and, therefore, is a risk factor for OSA, because an inferiorly placed hyoid bone places the geniohyoid muscle at a mechanical disadvantage by its angulation [26] Several factors have been hypothesised to influence the position of the hyoid bone. SFORZA et al. [24] suggested that obesity, through the deposition of fat around the neck, could be the cause of the downward displacement of the hyoid bone. FERGUSON et al. [33] reported that the distance between the hyoid bone and the mandibular plane increases in proportion to the circumference of the neck. TANGUGSORN et al. [25], and NELSON and HANS [18] found that the hyoid bone is in a lower position in obese patients, hypothesising that the hyoid movement is an adaptation to the increased size of the tongue that moves the tongue base lower in the hypopharynx, in turn reducing the patency of the upper airway. Other hypotheses for the downward and posterior migration of the hyoid bone with increased BMI include imbalance between the action of the suprahyoid and infrahyoid muscles, chronic snoring, repetitive chemical and mechanical stimuli, pharyngeal neuropathy, and neuromuscular factors [34, 35]. Finally, PAOLI et al. [23] hypothesised that the low position of the hyoid bone is more likely to be a consequence of OSA than a pre-existing anatomical abnormality; they posited that, over time, repeated apnoeas during the night might cause a lengthening of the hyoid ligaments.

Our data provide strong support for the hypothesis of TANGUGSORN et al. [25], and NELSON and HANS [18] that the enlarged tongue displaces the hyoid inferiorly and posteriorly. Specifically, we found that if we introduce tongue volume into our models as a covariate, there was no longer any difference in hyoid position between apnoeics and controls. Thus, we provide support for the concept that it is the enlarged tongue in apnoeics that leads to the alteration in the hyoid position.

This is clinically important because surgical procedures (i.e. hyoid advancement and suspension) have been developed to normalise the position of the hyoid. Such procedures are not addressing the fundamental issue. Thus, surgical procedures that alter the position or size of the tongue may be more beneficial. Surgical procedures to reduce tongue volume have been introduced [36-38] but in those studies, the effect on hyoid position was not addressed.

\section{Conclusions}

Analysis of three-dimensional MRI allowed us to accurately quantify craniofacial structures. The present study is the first study that has used MRI cephalometrics to examine the entire craniofacial structure in a large population. In our study population, the size of the mandible, rather than that of the the maxilla or angular measurements (SNA and SNB angles), was the most important risk factor for OSA. Alterations in mandibular structure, including shorter mandibular length and smaller mandibular depth, are independent risk factors for sleep apnoea in males, but not in females. In both males and females, apnoeics have an inferiorly displaced hyoid compared with controls. This difference was no longer found when tongue volume was introduced as a covariate. Thus, the inferiorposterior positioning of the hyoid bone in apnoeics is probably the direct result of the enlarged tongue volumes directly displacing the hyoid bone. These findings have important implications for the pathogenesis and treatment of sleep apnoea.

\section{STATEMENT OF INTEREST}

Statements of interest for A.I. Pack and R.J. Schwab can be found at www.erj.ersjournals.com/site/misc/statements.xhtml

\section{ACKNOWLEDGEMENTS}

The authors gratefully acknowledge E. Kim (University of Pennsylvania School of Medicine, Philadelphia, PA, USA) for the three-dimensional reconstruction MRI images of mandible, tongue and hyoid.

\section{REFERENCES}

1 Young T, Palta M, Dempsey J, et al. The occurrence of sleepdisordered breathing among middle-aged adults. $N$ Engl J Med 1993; 328: 1230-1235. 
2 McNicholas WT, Bonsigore MR. Sleep apnoea as an independent risk factor for cardiovascular disease: current evidence, basic mechanisms and research priorities. Eur Respir J 2007; 29: 156-178.

3 Young T, Finn L, Peppard PE, et al. Sleep disordered breathing and mortality: eighteen-year follow-up of the Wisconsin sleep cohort. Sleep 2008; 31: 1071-1078.

4 Ellen RL, Marshall SC, Palayew M, et al. Systematic review of motor vehicle crash risk in persons with sleep apnea. J Clin Sleep Med 2006; 2: 193-200.

5 George CF. Sleep apnea, alertness, and motor vehicle crashes. Am J Respir Crit Care Med 2007; 176: 954-956.

6 Punjabi NM, Polotsky VY. Disorders of glucose metabolism in sleep apnea. J Appl Physiol 2005; 99: 1998-2007.

7 Seicean S, Kirchner HL, Gottlieb DJ, et al. Sleep-disordered breathing and impaired glucose metabolism in normal-weight and overweight/obese individuals: the sleep heart health study. Diabetes Care 2008; 31: 1001-1006.

8 White DP. Sleep apnea. Proc Am Thorac Soc 2006; 3: 124-128.

9 Schwab RJ, Gupta KB, Gefter WB, et al. Upper airway and soft tissue anatomy in normal subjects and patients with sleepdisordered breathing. Significance of the lateral pharyngeal walls. Am J Respir Crit Care Med 1995; 152: 1673-1689.

10 Schwab RJ, Pasirstein M, Pierson R, et al. Identification of upper airway anatomic risk factors for obstructive sleep apnea with volumetric MRI. Am J Respir Crit Care Med 2003; 168: 522-530.

11 Haponik EF, Smith PL, Bohlman ME, et al. Computerized tomography in obstructive sleep apnea. Correlation of airway size with physiology during sleep and wakefulness. Am Rev Respir Dis 1983; 127: 221-226.

12 Shelton KE, Woodson H, Gay S, et al. Pharyngeal fat in obstructive sleep apnea. Am Rev Respir Dis 1993; 148: 462-466.

13 Guilleminault C, Riley R, Powell N. Obstructive sleep apnea and abnormal cephalometric measurements. Implications for treatment. Chest 1984; 86: 793-794.

14 Lowe AA, Fleetham JA, Adachi S, et al. Cephalometric and computed tomographic predictors of obstructive sleep apnea severity. Am J Orthod Dentofacial Orthop 1995; 107: 589-595.

15 Lowe AA, Santamaria JD, Fleetham JA, et al. Facial morphology and obstructive sleep apnea. Am J Orthod Dentofacial Orthop 1986; 90: 484-491.

16 Lyberg T, Krogstad O, Djupesland G. Cephalometric analysis in patients with obstructive sleep apnoea syndrome. I. Skeletal morphology. J Laryngol Otol 1989; 103: 287-292.

17 Miles PG, Vig PS, Weyant RJ, et al. Craniofacial structure and obstructive sleep apnea syndrome: a qualitative analysis and meta-analysis of the literature. Am J Orthod Dentofacial Orthop, 1996: 163-172.

18 Nelson S, Hans M. Contribution of craniofacial risk factors in increasing apneic activity among obese and nonobese habitual snorers. Chest 1997; 111: 154-162.

19 Schwab RJ, Pack AI, Gupta KB, et al. Upper airway and soft tissue structural changes induced by CPAP in normal subjects. Am J Respir Crit Care Med 1996; 154: 1106-1116.

20 Schwab RJ, Pasirstein M, Kaplan L, et al. Family aggregation of upper airway soft tissue structures in normal subjects and patients with sleep apnea. Am J Respir Crit Care Med 2006; 173: 453-463.

21 Okubo M, Suzuki M, Horiuchi A, et al. Morphologic analyses of mandible and upper airway soft tissue by MRI of patients with obstructive sleep apnea hypopnea syndrome. Sleep 2006; 29: 909-915.

22 Iked N, Hazime N, Dekeister C, et al. [Comparison of the cephalometric characteristics of snoring patients and apneic patients as a function of the degree of obesity. Apropos of 162 cases]. Rev Stomatol Chir Maxillofac 2001; 102: 305-311.

23 Paoli JR, Lauwers F, Lacassagne L, et al. Craniofacial differences according to the body mass index of patients with obstructive sleep apnoea syndrome: cephalometric study in 85 patients. $\mathrm{Br} \mathrm{J}$ Oral Maxillofac Surg 2001; 39: 40-45.

24 Sforza E, Bacon W, Weiss T, et al. Upper airway collapsibility and cephalometric variables in patients with obstructive sleep apnea. Am J Respir Crit Care Med 2000; 161: 347-352.

25 Tangugsorn V, Krogstad O, Espeland L, et al. Obstructive sleep apnoea: multiple comparisons of cephalometric variables of obese and non-obese patients. J Craniomaxillofac Surg 2000; 28: 204-212.

26 Lowe AA, Ozbek MM, Miyamoto K, et al. Cephalometric and demographic characteristics of obstructive sleep apnea: an evaluation with partial least squares analysis. Angle Orthod 1997; 67: 143-153.

27 Pierson RW, Pack AI, Maislin G, et al. Identification of craniofacial risk factors for obstructive sleep apnea using novel $\mathrm{mr}$ cephalometric techniques. Am J Respir Crit Care Med 2003; 167: A601.

28 Rechtschaffen A, Kales A, eds. A Manual of Standardized Terminology: Techniques and Scoring System for Sleep Stages of Human Subjects. Los Angeles, Brain Information Service/Brain Research Institute, 1968.

29 Steiner CC. The use of cephalometrics as an aid to planning and assessing orthodontic treatment. Am J Orthod 1960; 46: 721-735.

30 Banabilh SM, Suzina AH, Dinsuhaimi S, et al. Cranial base and airway morphology in adult malays with obstructive sleep apnoea. Aust Orthod J 2007; 23: 89-95.

31 Guilleminault C, Quera-Salva MA, Partinen M, et al. Women and the obstructive sleep apnea syndrome. Chest 1988; 93: 104-109.

32 Lowe AA, Ono T, Ferguson KA, et al. Cephalometric comparisons of craniofacial and upper airway structure by skeletal subtype and gender in patients with obstructive sleep apnea. Am J Orthod Dentofacial Orthop 1996; 110: 653-664.

33 Ferguson KA, Ono T, Lowe AA, et al. The relationship between obesity and craniofacial structure in obstructive sleep apnea. Chest 1995; 108: 375-381.

34 Friberg D, Ansved T, Borg K, et al. Histological indications of a progressive snorers disease in an upper airway muscle. Am J Respir Crit Care Med 1998; 157: 586-593.

35 Mezzanotte WS, Tangel DJ, White DP. Influence of sleep onset on upper-airway muscle activity in apnea patients versus normal controls. Am J Respir Crit Care Med 1996; 153: 1880-1887.

36 Steward DL. Effectiveness of multilevel (tongue and palate) radiofrequency tissue ablation for patients with obstructive sleep apnea syndrome. Laryngoscope 2004; 114: 2073-2084.

37 Stuck BA, Maurer JT, Verse T, et al. Tongue base reduction with temperature-controlled radiofrequency volumetric tissue reduction for treatment of obstructive sleep apnea syndrome. Acta Otolaryngol 2002; 122: 531-536.

38 Terris DJ, Kunda LD, Gonella MC. Minimally invasive tongue base surgery for obstructive sleep apnoea. J Laryngol Otol 2002; 116: 716-721. 